\title{
A Disconnect in Representation? Comparison of Trends in Congressional and Public Polarization*
}

\author{
Seth J. Hill ${ }^{\dagger} \quad$ Chris Tausanovitch ${ }^{\ddagger}$
}

\begin{abstract}
While it is widely agreed that Congress has polarized over the past 40 years, there is considerable disagreement about the extent of public polarization and its connection to congressional polarization. We present the first estimation of time series of polarization using the same method on the most comprehensive data for both the public and the Senate. With statistics of various definitions of polarization, we find little increase in the dispersion of views in the public from 1956 to 2012, but do find an increase in ideological sorting starting around 1980. The two time series bear little resemblance to one another with respect to divergence. Further, while congressional sorting exceeds that in the public today, we find that Congress has always been unrepresentative of the public. These results suggest that it is unlikely that changes in public preferences alone explain the widening gulf between the two parties in Congress.
\end{abstract}

*An earlier version of this paper was presented at the MPSA National Conference, April 2013 under the name "Non-Polarization in the American Public" and the Annual Meetings of the American Political Science Association, August 2013. We thank participants in a seminar at UCSD, Alan Abramowitz, Scott Desposato, Kyle Dropp, Greg Huber, Bill Jacoby, Stephen Jessee, Matt Levendusky, Jeff Lewis, John Patty, Lynn Vavreck, and Chris Warshaw for feedback. Tausanovitch thanks the UCLA Center for American Politics and Public Policy for support, and Knox Brown for research assistance. Supplemental information is available at http://www.sethjhill.com/working/ HillTausanovitch_Polarization_Appendix.pdf.

${ }^{\dagger}$ Assistant Professor, Department of Political Science, University of California, San Diego; s jhill@ucsd. edu, http: //www. sethjhill.com.

${ }^{\ddagger}$ Assistant Professor, Department of Political Science, University of California, Los Angeles; ctausanovitch@ ucla.edu, http://www. christausanovitch.com. 
By any measure, the modern Congress is a polarized one. In the past 40 years, retiring Republicans have been replaced by more conservative Republicans, and incoming Democrats have been more liberal than those that they replaced. The departure of Southern Democrats, once a stronghold of moderate views on issues besides civil rights, has exacerbated this trend. In the 1950s, political scientists complained that it was difficult to differentiate between the two parties. By the 1980s the parties in Congress were mostly differentiated and today ideological overlap between the parties is essentially gone. Congressional polarization may be the most prominent stylized fact of American political science, and finding its source has become one of our most important research questions (Poole and Rosenthal, 2000).

In contrast to Congress, studies of polarization in the public have come to conflicting conclusions. Fiorina and Abrams (2008) argue that "The most direct evidence ... shows little or no indication of increased mass polarization over the past two to three decades." Abramowitz and Saunders (2008), in contrast, argue that "our evidence indicates that since the 1970s, ideological polarization has increased dramatically among the mass public in the United States as well as among political elites." Jacobson (2004) agrees, providing evidence that "the increase in [Congressional] polarization is strongly related to the growing differences between the two parties' respective electoral coalitions." And yet Levendusky (2009a) agrees with Fiorina and Abrams (2008), arguing that "while there has been a large degree of elite polarization and voter sorting, there has been only a much more limited amount of mass polarization." The existence of polarization in the public continues to be disputed among top scholars.

We offer here an attempt to resolve the empirical measurement of public polarization by applying the method used to establish near universal consensus on polarization in the Congress. We apply a measurement model to both the public and the Senate similar to the NOMINATE procedure. Having used the same method to measure polarization in both settings, we can use polarization in Congress as a benchmark by which to judge polarization in the public. This method allows us to compare trends in specific statistics of polarization measured in the same way in both sets of data over time. 
Part of the disagreement about public polarization is definitional. In this paper we focus on two widely recognized notions of polarization. We term the first "divergence" in reference to the degree to which the distribution of opinion is spreading apart or, to put it another way, members of the public are moving towards the extremes. The second definition is commonly referred to as "sorting" or "party sorting" and refers to the extent to which ideological positions correspond with party identification. The major point of dispute in the existing literature is whether sorting in the public reflects underlying divergence, or is merely a function of changes in the composition of the parties.

Disentangling sorting from divergence is empirically complicated. Previous work may have come to divergent conclusions because different scholars choose different survey questions to measure polarization. ${ }^{1}$ The fact that choice of survey question apparently leads to different conclusions about polarization is problematic. Second, different scholars offer different interpretations of the same magnitudes. For instance, Fiorina, Abrams, and Pope (2008) show that about five percent of the public switched to the most extreme category on a question about jobs and standards of living from 1984 to 2004. They call this a "marginal" change, but their critics disagree.

Whether or not the public has polarized along with Congress is of central relevance to our understanding of American politics and representation, making the lack of consensus troubling. If voters are more divergent, then they may be responsible for the level of polarization in Congress and other changed aspects of our political system. If voters have not polarized, then Congress may not reflect the underlying views it is supposed to represent. Fundamental questions of democratic representation are at stake in the relationship between polarization in the public and in Congress. Indeed, the debate is of sufficient interest to merit consideration in the top journals of other fields of social science (e.g. Baldassarri and Gelman, 2008; Krasa and Polborn, 2014).

We measure polarization using some of the best data available, which includes a large set of ideological policy questions in a long-running professional opinion survey, the American National Election Studies. Using a measurement model based on responses to multiple questions from each

\footnotetext{
${ }^{1}$ For example, some focus on specific policy issues while others focus on self-reported ideology.
} 
individual rather than responses to single questions to gauge polarization in the public offers three advantages. First, summaries of multiple questions are used to measure polarization in Congress (i.e. roll call votes used to estimate NOMINATE), lending the method validity in measurement. Second, summarizing all available policy questions reduces the importance of any particular question to the analysis, reducing the analyst's discretion and its influence on conclusions. Third, summarizing multiple questions helps mitigate error in the measurement of citizen preferences.

For decades, measurement of polarization in Congress and the state legislatures has been facilitated by the hundreds of roll calls that representatives make each year. Measurement of polarization in the electorate, however, is more of a challenge. Not only do average citizens not cast any roll call votes, but most pay limited attention to political issues. Citizens may only have well-formed opinions on a few political topics, making measurement of underlying preference structures difficult even if we could ask them to cast roll call votes - many of these votes would be much more noise than signal. Using the scaling models that are applied to Congress to measure public preferences is a natural way both to combine information from multiple responses and to correct for measurement error (Ansolabehere, Rodden, and Snyder, 2008). Indeed, this technique is not new (e.g. Aldrich and McKelvey, 1977; Jacoby, 1994; Treier and Hillygus, 2009), and its introduction into the debate on public polarization is in our view long overdue.

In this article, we estimate and compare time series of polarization back to the 1950 s in the public and Congress using the same statistical model and the most comprehensive data sets available. We estimate multiple statistics to characterize polarization in a unified Bayesian framework accounting for differential uncertainty about the public due to varying numbers of policy questions across years. We find that divergence in public ideology has hardly changed since 1956, with no apparent trend. Divergence in the Senate, in contrast, has increased steadily and dramatically. We find evidence of sorting in the public beginning around 1980, with a somewhat greater correspondence between ideology and party today than there was in the 1950s. However, the Senate has always been far more sorted than the public and remains so. Even in its least sorted year, ideological overlap between the parties was always less than $50 \%$ of the Senate's membership and more 
than $50 \%$ of the overall variance in ideology was between-party. In contrast, most of the variance in public views has been within-party, and the overlap has always been greater than $50 \%$. Sorting in the public may be meaningful, but our more substantial finding is that the Senate has always differed starkly from the public in terms of party sorting as well as the trend in divergence, even in the less polarized era of the 1950s and 1960s.

In our view, the large difference between the Senate and the public in terms of partisan composition of ideology is more significant than the small amount of sorting in the public. When the Senate is much more sorted than the public, senators are inevitably unrepresentative of most of their constituents, even those in the same party, because American citizens account for a more continuous spectrum of viewpoints. The fact that senators have become far more divergent in their views at a time when the public has hardly budged confirms that the connection between public ideology and senate ideology is weak in aggregate. While some authors have argued that congressional polarization is causing a breakdown in representation (Fiorina and Abrams, 2012), our results show that a weak aggregate electoral link is the norm over the past 60 years, not the exception.

A further implication of the difference between the public and the Senate is that the distribution of ideology of the public as a whole is an unlikely candidate for explaining Congressional divergence. Even the trend towards greater sorting in the public is limited. It is unclear why a small amount of sorting in the public would lead to a large divergence in Congress. It is more likely, as some have argued, that sorting in the public is a consequence rather than a cause of polarization (Levendusky, 2010).

The following section briefly reviews the literature on polarization. We follow this with a description of our Bayesian item-response theory method, and describe the roll call vote and public opinion survey data that we use for estimation. In the results section, we contrast polarization in the public with polarization in the Senate. We present three alternative specifications for robustness, and conclude with a summary of our findings and their implications. 


\section{Literature on polarization}

Empirical definitions of polarization vary, but most definitions relate to one of two concepts. First,

polarization is divergence in political ideology between members of the public. For example, if more members of the public adopt extreme ideology or if fewer members of the public occupy the middle of the distribution, the public is more polarized. Second, polarization is increasing separation or sorting of clearly defined groups, for example, if Democrats become more liberal and Republicans more conservative. A long literature shows that by either definition, Congress has become more polarized (Theriault, 2006; McCarty, Poole, and Rosenthal, 2006; Poole and Rosenthal, 2000, 1984). Evidence that contributors and activists have polarized is likewise strong (McCarty, Poole, and Rosenthal, 2006; Layman and Carsey, 2002; Layman et al., 2010).

Less certain is how much citizens are leading, following, or diverging from the polarization of political elites. The focal debate over the existence of polarization in the broader public has been conducted primarily between Fiorina, Levendusky, Pope, and Abrams (Fiorina and Abrams, 2012, 2008; Fiorina, Abrams, and Pope, 2005, 2008; Levendusky, 2009b,a) and Abramowitz, Saunders, and Jacobson (Abramowitz, 2010; Abramowitz and Saunders, 2008, 2005; Jacobson, 2003, 2004). The second set of scholars argues that the public is polarized, and that Americans have changed their partisanship and other attributes to reflect their ideological allegiance to deeply divided opposing camps. The first set of scholars argues that evidence of public polarization is a mere epiphenomenon, reflecting a re-grouping into the appropriate parties of a public whose political views and attitudes have changed little.

The measurement of divergence and sorting in the public is more difficult than it is in Congress. While members of Congress cast hundreds of roll call votes each year, data on the political positions of the public is typically much more limited. Survey respondents are known to change their responses from survey to survey, providing noisy signals of their underlying ideologies at any given moment. Some work in this literature focuses on individual survey questions, exacerbating this measurement problem. Further, as we show below, changes in public views have been much smaller than changes in Congressional views, making them more difficult to detect statistically. 
Fiorina, Abrams, and Pope (2005) offer two critiques that are important to keep in mind when measuring polarization. First, that there is a difference between a "closely divided" public and a "deeply divided" public. In a closely divided public, many policy choices may be split at margins close to 50-50, even if members of the public are almost indifferent about those issues. For instance, every voter may like both presidential candidates about equally well, and flip a coin to make their choice. In a deeply divided public, half the voters have a very strong preference for one candidate, and half the voters have a very strong preference for the other. This is a very different situation that still leads to a public split 50-50. Margins are not enough to tell us whether a public is polarized. Rather, the correlation of preferences across multiple choices is central.

The second critique presented in Fiorina, Abrams, and Pope (2005) is that uniform shifts in the population's beliefs do not mean greater dispersion in those views. As an example, Fiorina, Abrams, and Pope (2005) note that public opinion in the 1970s was highly unfavorable towards homosexuals, but now is much more supportive. If Americans are simply uniformly more liberal on gay issues, then no polarization has occurred. If, on the other hand, some Americans have become less tolerant towards homosexuals and others have become more tolerant, then the public is more polarized.

In this paper, we will define ideology in the same manner as the literature on Congress. We argue that Americans have some underlying policy beliefs or values (what we call ideologies, broadly construed) that structure their responses to specific policy questions. Responses to particular policy questions allow us to estimate this latent construct. We can then look at changes over time in the distribution of ideology as well as the relationship between ideology and political party - divergence and sorting, respectively.

We believe it is important to consider how a set of attitudes or beliefs go together (or do not) across a population as well as the extremity of the attitudes. Looking at many attitudes as a manifestation of underlying ideology allows us to separate the signal from the noise. For instance, if people who are becoming more liberal on gay rights also become more liberal on other issues, this is indicative of an ideological shift to the left, rather than simply a national trend towards 
acceptance of homosexuality. Our measure of ideology explicitly accounts for the notion that systematic changes in ideology should be reflected in multiple survey responses, just as measures of congressional ideology assume that preferences should be reflected in multiple roll call votes.

Armed with our measure of ideology, we can look at whether survey respondents and legislators have become more divergent or more sorted. Ideology as we define it is a continuous variable, so we can analyze it's dispersion as we would any other continuous variable. ${ }^{2}$ We need not assume and identify ex ante that certain responses are extreme or moderate. If the distribution becomes more dispersed, then individuals are more divergent. If ideology becomes more highly associated with party, then individuals have sorted. If sorting occurs but not divergence, then the effect is merely compositional: Individuals are not moving to the extremes, but party affiliation is brought more in line with ideology.

\section{A multinomial item-response model to measure ideology}

In this section, we present the statistical model we use to estimate ideology in the public and the Senate in a common framework from the 1950 s to the present. ${ }^{3}$ Our IRT model is similar to the common DW-NOMINATE model used by Poole and Rosenthal (2000) to estimate the ideology of members of Congress. Clinton, Jackman, and Rivers (2004b) use the IRT model in the Congressional roll call voting context, but it has since been adapted to estimate the ideology of members of the public (Bafumi and Herron, 2010; Jessee, 2009; Tausanovitch and Warshaw, 2013; Treier and Hillygus, 2009). The objective of IRT is to measure a continuous latent variable using responses to a set of questions that are a function of that latent variable. In this case, we observe responses to government policy questions, and we want to estimate the ideological positions underlying these responses.

Most previous IRT-like models of the ideology of the American public have collapsed survey questions with multiple response categories to binary outcomes, for example recoding a question

\footnotetext{
${ }^{2}$ We relax the assumption of cardinality below by analyzing various rank statistics of polarization.

${ }^{3}$ We choose to use the Senate only to the exclusion of the House of Representatives because patterns of polarization are remarkably similar across the two chambers (as documented by Poole and Rosenthal, 2000) and the Senate is more computationally tractable given the smaller number of senators.
} 
to yes and no even if there are options to strongly or somewhat agree or disagree (for an exception, see Treier and Hillygus, 2009). Because placement in extreme categories is often of interest (Abramowitz and Saunders, 2008), we use a categorical response model that does not require us to collapse end response categories with middle categories (see Lo, 2010, chap. 4 for the estimation of a categorical DW-NOMINATE model). This is simply a generalization of the common binary model - in a context where there are two response categories, the two models are interchangeable.

Our estimation strategy is Bayesian, which offers a few crucial improvements and no drawbacks save for computing time. First, the method is effective in dealing with the sparseness of policy opinions in the survey data, handling such missingness within the main estimation. Second, the method allows us to calculate uncertainty and make inferences about functions of the estimates for the Senate and the public, for example putting confidence intervals on statistics of sorting and dispersion. This allows us to differentiate sampling variability from actual changes in opinions and behavior. Third, and related to this inference, we do not make comparisons solely on point estimates for individuals or senators, but rather on the entire posterior distributions of these estimates. As we will show below, this improvement leads to a notably different interpretation of polarization in the public, with point estimates suggesting polarization, but summaries of full posterior beliefs suggesting no polarization.

To summarize the above, our approach has two main advantages over more common approaches: the multinomial model takes advantage of information from all the response categories rather than arbitrarily reducing them to two, and the Bayesian estimation allows us to easily handle missing data and to do inference on quantities that would be highly unwieldy in a maximum likelihood setting. Otherwise, the method is extremely similar to NOMINATE and it's cousin, the quadratic utility item response model. In fact, our estimates for senator ideology correlate with DW-NOMINATE estimates at 0.96 overall, 0.89 for Democrats and 0.86 for Republicans. Readers who wish to skip to the results may safely think of our method as merely NOMINATE with estimates of uncertainty on quantities related to polarization.

We start by assuming a one-dimensional issue space. Let $x_{i}$ denote person $i$ 's latent ideology, 
and $y_{i j}$ denote person $i$ 's response to question $j$, where $y_{i j}=k$ indicates response $k$ to question $j$, with $K_{j}$ response options for question $j$, which may vary across questions. Then, the probability that person $i$ chooses response $k$ to question $j$ is

$$
\operatorname{Pr}\left(y_{i j}=k\right)=\frac{\exp \left(\beta_{j k} x_{i}-\alpha_{j k}\right)}{\sum_{l=1}^{K_{j}} \exp \left(\beta_{j l} x_{i}-\alpha_{j l}\right)}
$$

where $\alpha_{j k}$ and $\beta_{j k}$ are the item parameters for response $k$ to question $j$. The likelihood model here is a multinomial logit, and the item parameters define the relative likelihood of response $k$ to some baseline response category, usually $k=1$ by constraining $\beta_{j 1}$ and $\alpha_{j 1}$ to zero. $^{4}$

The complete likelihood is simply the product of all of the individual likelihoods for each observed response

$$
\prod_{i \in I} \prod_{j \in J} \prod_{k \in K_{j}}\left(\frac{\exp \left(\beta_{j k} x_{i}-\alpha_{j k}\right)}{\sum_{l=1}^{K_{j}} \exp \left(\beta_{j l} x_{i}-\alpha_{j l}\right)}\right)^{I\left(y_{i j}=k\right)}
$$

where $I$ is the set of all people, $J$ is the set of all items, and $I\left(y_{i j}=k\right)$ takes the value of 1 if respondent $i$ gave response $k$ to question $j$, and 0 otherwise.

As with the standard multinomial regression model, to identify the parameters of our multinomial item-response model we require constraints on both the $\alpha$ and $\beta$ item parameters, and on the scale and location of the $x_{i}$ s. We set $\beta_{j 1}$ and $\alpha_{j 1}$ to zero for all $j$ so that response option 1 serves as the baseline category. To identify the scale of ideology, we normalize the estimates of the $x_{i}$ to mean 0 and variance 1 . We implement the scale normalization with post-processing.

\section{Data}

We estimate ideology from a set of 67 policy questions asked in different years from 1956 to 2012 in the time series of the ANES. We draw most of these questions from the ANES Time Series Cumulative Data File. ${ }^{5}$ We supplemented the cumulative file with 19 additional items from the 1956 through 1966 ANES cross sections not present in the Cumulative File because of the

\footnotetext{
${ }^{4}$ In Appendix Section E.1, we present results from a model using an ordered logit likelihood. Results are highly similar.

${ }^{5}$ We use the September 2014 release, and use only the face-to-face interviews from 2012 . While the cumulative file begins with the 1948 study, we were unable to locate items that are asked in multiple years for 1948, 1952, or 1954, and thus our time series begins in 1956.
} 
small number of items in the cumulative file from these early years. ${ }^{6}$ We present a tabulation of the number of items and non-missing responses by year and by party identification in On-line Appendix Table A1. We analyze more than 750,000 non-missing responses to policy items for the more than 50,000 respondents to this set of surveys.

In Figure 1, we present the full set of questions that we use in our analysis. The most important feature of this graphic is the substantial repetition of questions across years. Repeated questions "glue" our scale together across different years. For instance, one question asked in 1956 is also asked in 2012. More importantly, there is significant overlap across many different sets of years. This ensures that a large number of questions tie 1966 to 1972, a large number of questions tie 1972 to 1980 and so on. The assumption that these common items can be held fixed across years allows us to compare ideology over time, just as similar assumptions allow the comparison of Congresses over time (e.g., in the DW-NOMINATE model). We should note that this assumption need not be correct - if questions have different meanings in different years then the item parameters would be different if each year were estimated separately. In our case, we consider this assumption an approximation. We can think of no other way to define polarization but with reference to a set of items whose average meaning is held constant over short to medium lengths of time. It should be noted that studies focusing on single items are even more susceptible to this problem: When inferences rely on one item alone, change in the meaning of that item will not average out. Our procedure using multiple overlapping items provides a greater opportunity for changes in question meaning to average out across items. ${ }^{7}$

In Appendix Section B, we analyze a fixed set of ten policy questions asked in each of ten different releases of the Study, 1984 to 2008 to show that our results do not depend upon a varying set of items. We find broadly similar results: little evidence of divergence and evidence of modest

\footnotetext{
${ }^{6}$ To gather additional items for 1956-1966, we first perused the cross-sectional codebooks from each study for policy (with the exclusion of foreign policy) items, then manually matched items and responses across studies where the questions were equivalent, and merged responses to these items to the cumulative file based on respondent case identifier. We checked the validity of the merge by comparing the age variable from the cross-section to the age variable in the cumulative file, and found a perfect match. Further details on this collection are available from the authors on request.

${ }^{7}$ In Appendix Section E.3, we present results from an estimation that relaxes the requirement of items to have constant meaning over many decades. Results are highly similar.
} 
sorting. It is useful to look at these ten questions as an example of how the present paper differs from studies focusing on individual survey questions. We present the proportion of each sample giving each response in each year in Figure 2. Each shaded box is the survey-weighted proportion of respondents giving that response to that question in that year, with larger boxes indicating more respondents in that category. We shade the boxes for comparison so that the same category is the same shade of gray in each year. We also plot the distributions of 7-point party identification and 7-point ideology for reference (including the "don't know" category, which is the large category at the bottom of that frame), though these two questions do not enter our item-response model.

The response margins in Figure 2 provide preliminary evidence that the electorate is not moving strongly in aggregate opinion on major political questions from 1984 to 2008 . We do not see broad movements toward the edge categories in any question. Instead, we see mostly stable responses to the ten policy questions and to the identification with party and ideology. As noted above, however, the marginals do not tell the whole story. It may be that individual responses to these policy questions are becoming more correlated over time, and that this correlation is symptomatic of polarized ideology in the absence of noticeable change in the population marginal totals. Our measure of ideology will allow us to take account of 67 questions rather than 10.

To estimate polarization in the American public on a longer time horizon, we implement the model presented above with the varying sets of items in different years of the ANES. We estimate our Bayesian model using the software JAGS (Plummer, 2013a,b). We use the response categories as coded in the ANES cumulative data file, and set "don't know" responses to missing. ${ }^{8}$ We use normal priors over all $\alpha, \beta$, and $x$, except for the identifying restriction that $\alpha_{j 1}, \beta_{j 1}=0 \forall j$. We burn in the model for 500 iterations, and then draw 10,000 posterior samples, which are thinned by $2 .^{9}$

\footnotetext{
${ }^{8}$ Setting don't know as a separate multinomial category pulls a one-dimensional model toward a dimension of likelihood of don't know response, which are prevalent and highly correlated across questions.

${ }^{9}$ All but $0.06 \%$ of the parameters have the maximum iterations recommended by the Raftery statistic with parameters $\mathrm{q}=0.025, \mathrm{r}=0.01$ and $\mathrm{s}=0.95$, and all achieve the minimum recommended iterations. $94.5 \%$ of the parameters have Geweke statistics with absolute values less than 1.96. The mean absolute value of the autocorrelation of the thinned parameters is 0.067 . In a shorter run of 3 chains of 2,000 iterations, $0 \%$ of the parameters had estimated potential scale reduction factors (PSRFs) of greater than 1.1, and only $0.09 \%$ failed to reject PSRFs of greater than 1.1, ala the Gelman and Rubin diagnostic.
} 
To place our results from the ANES in context, we run a similar IRT model on roll call votes from the U.S. Senate for this same time period. Our model for Senate voting is almost identical to our model for voter choice on surveys but for two differences. First, votes in Congress only record two responses: yea or nay. As a result, the multinomial model collapses to the more common binary logit response model for senators. Second, we do not possess common items to glue the scale across time. Instead, we glue the scale across time by treating the ideology of each senator as fixed for the time period of our study, similar to the assumptions in DW-NOMINATE. ${ }^{10}$

We use the congressional roll call votes compilation of Jeffrey B. Lewis, Keith Poole and Howard Rosenthal (Carroll et al., 2009). It comprises 1.9 million non-missing roll call votes cast by 542 senators since 1956 . We use the same priors over the item parameters that we use for voters, and again draw 10,000 posterior samples after 500 iterations of burn-in. ${ }^{11}$

\section{Estimates of ideology in the public and Senate}

We turn now to presentation of our results. We present graphical summaries and use the parameters from the model to assess the prevalence of polarization. We first discuss the rationale for focusing on inference rather than point estimates, then test for the presence of divergence and party sorting.

In Figure 3, we plot two different ways of computing divergence (summarized by standard deviation) in ideology for members of the public. One common way to compute spread is to take the point estimates for each individual and compute their standard deviation for each year. These estimates are the grey squares in Figure 3. However, there is a problem with this approach. Point estimates do not take account of uncertainty. In some years we have as few as three questions, and our resulting uncertainty about each individual's ideology is substantial. As a result, while our point estimate for many individuals will be close to 0 , the model is not very certain about these locations. For instance, if a voter tells us that the government should ensure fair jobs and housing

\footnotetext{
${ }^{10}$ We view the assumption that senators do not move over time as a conservative way to estimate polarization in the Senate. If senators move over their careers toward the extremes, we fail to capture this movement. Only if continuing senators are becoming more moderate over time will this assumption lead to an understatement of polarization.

${ }^{11} 100 \%$ of the parameters have greater than the number of iterations recommended by the Raftery diagnostic, suggesting convergence of the Markov chain. Our results using this method conform very closely to results found using the standard DW-NOMINATE procedure for scaling legislative ideology.
} 
for blacks, we learn, albeit with some uncertainty, that the voter is not a staunch conservative in 1958. But we learn little about exactly how liberal that person is. The point estimate might be only a little to the left, and so if we use the point estimate we conclude that this is a moderate. But a glance at the posterior distribution (which is for practical purposes analogous to a standard error in the maximum likelihood framework) shows that this person could well be an extreme liberal because we have very little certainty about their individual position. We have more certainty about features of the distribution of all individuals than we do about the ideological location of each individual.

The correct method in this case directly measures both spread and uncertainty in spread. The quantity of interest is the standard deviation of ideology, which we summarize across a set of posterior MCMC samples. On each posterior MCMC sample, we calculate the standard deviation of the ideal points in each survey year. The median, 2.5 th, and 97.5 th percentiles of these draws are our point estimate and credible interval for the spread of ideology in each year. We plot these results as black circles in Figure 3.

The conclusions that we draw from the black circles are notably different from the story of the grey squares. To highlight this difference, we plot simple regression lines through both clouds of dots. Using the grey squares, one would conclude that polarization had increased. However, this would be incorrect. Lower standard deviations in earlier years results from the smaller number of questions asked in those earlier years: Uncertainty about individual ideology is greater, leading posterior median values for each individual closer to the prior median of zero. In contrast, posterior beliefs about the standard deviation of ideology in each year correctly summarized by the black circles are not much different in the later years than in the earlier years. If anything, the estimation suggests that spread has decreased. However, because we can construct credible intervals using the correct procedure, we can see that the spread in most years is not statistically distinguishable from one another. ${ }^{12}$

\footnotetext{
${ }^{12}$ In Appendix Section C, we present raw histograms of the distributions of ideology using both point estimates. The histograms that only use point estimates seem to point to a pattern of polarization, but are contradicted by the histograms that take account of uncertainty, which are remarkably consistent. These results assure us that the prior is not having too much of an impact on our results, because we know that having more data permits separation among
} 
The difference between these two methods highlights the importance of taking proper account of uncertainty, and the advantages of Bayesian methods. ${ }^{13}$ Bayesian methods make it simple to compute credible intervals for quantities that were not parameterized directly in the statistical model, and thereby allow us to take account of uncertainty due to variation in our statistical power to detect polarization.

\section{Polarization in the American public and the Senate}

In this section, we assess if there has been an increase in the divergence of ideology of the American public from 1956 to 2012. We compare the distribution of our estimates of ideology over time to see if the standard deviation of the distribution of ideal points has increased. We also look at the year over year replacement by more divergent individuals. In the public, we find little evidence of increasing divergence. We contrast this with consistently increasing divergence among senators. In the following section, we assess changes in sorting of party and ideology.

Perhaps one of the most intuitive measures of polarization is the variance of the distribution of ideology of the population. Higher variance in this distribution would follow from various changes in underlying ideology consistent with polarization. For example, if more members of the public had extreme preferences or if more members of the public moved away from the middle even if not all the way to the extremes - or, both - the distribution would have higher variance, all else equal. If ideology is diverging in either of these ways, then the standard deviation of the distribution of ideology would capture polarization.

Figure 4 suggests that any increase in variation in the views of the public, if one occurs at all, is small. In order to estimate the actual spread of the distribution in each year, we calculate the standard deviation of the distribution of ideal points for each year within each iteration of our MCMC sample. ${ }^{14}$ The distribution of the standard deviation across MCMC samples summarizes

the point estimates.

${ }^{13}$ For more detail on the advantages of Bayesian methods for performing inference on quantities other than the directly estimated parameters, see Jackman (2009). For an example that puts this method into practice, see Clinton, Jackman, and Rivers (2004a).

${ }^{14}$ This is the same set of estimates as the black circles in Figure 3. 
our posterior beliefs about the standard deviation in each year. ${ }^{15}$ In Figure 4, we plot the median posterior standard deviation along with a $95 \%$ credible interval for each year. As noted above, the scale of ideology is arbitrary, so the standard deviation of all ideal points across all years is set to 1 , and the standard deviation in each individual year is relative to this value. If variance in ideology were increasing from 1956 to 2012, we should see standard deviations below 1 in the early years and standard deviations above 1 later in the series. ${ }^{16}$

Our results for survey respondents in Figure 4 show two trends. First, the estimated standard deviation changes little from 1956 to 2012. One way to analyze the data is to look at the endpoints. In 1956, the estimated standard deviation is slightly greater than 1. In 2012, the standard deviation is about $5 \%$ above 1 . The difference is not statistically significant, with large overlap in the two credible intervals. Substantively, there is no estimated divergence as great as $10 \% .{ }^{17}$

Second, the estimated fluctuations do not appear to follow a clear over-time trend. The years of lowest and highest standard deviations occur in the middle of this time period (1992 and 1970), though the credible intervals do not allow us to make these distinctions at standard levels of statistical significance. In fact, of the 7 years that are significantly greater than 1, only one has occurred since 1985 while all eight of the years that are significantly less polarized have occurred since $1980 .{ }^{18}$ In fact, if we separate the data into one early and one late time period, we would conclude that the standard deviation of views in the public has decreased in the latter time period. The strongest conclusion to draw is that the spread of public ideology appears to fluctuate within a narrow band.

\footnotetext{
${ }^{15}$ We calculate the standard deviation only for the ideal points of the respondents we observe, so it does not account for sampling error due to limited ANES sample sizes. As a result, this estimator will tend to reject the null hypothesis too often, because differences in sample sizes lead to differences in precision. We use post-stratification survey weights from all studies where they are available in all calculations of population statistics (means, medians, variances, percentiles, etc.).

${ }^{16}$ We plot a separate series for respondents to the ANES and senators. The standard deviations from each series are linked only by a statistical identification restriction, so only relative changes within each series should be compared.

${ }^{17}$ In Appendix Section D, we present the results of a monte carlo experiment in which we show that even 10 questions (far fewer than we have in most years of our sample) is enough to capture increases in the standard deviation of $10 \%$ or more using our model and with our sample sizes of voters. This suggests that our failure to measure an increase in variance is not due to low statistical power.

18 Two features of the estimates preclude a strong conclusions about individual years: first, that we have not accounted for sampling error, and second, that there is a multiple testing problem in testing each year individually.
} 
For senators, the contrast is apparent. There is an increase in standard deviation over time, and the magnitude is dramatic. Polarization, by this measure of spread, increased by $35 \%$ from the 1960s to the present. This well-known finding dwarfs the small fluctuations in the variance of voter ideology, and demonstrates a disconnect between the two series. We note that this disconnect is present in 1956 as in 2012, though the magnitude appears more divergent at the end of the series.

Although we do not find increases in the variance of public preferences, other features of the distribution consistent with polarization could be unnoticed by this simple summary. For instance, some voters could become more moderate while extreme voters could become more common, keeping the population standard deviation relatively unchanged. ${ }^{19}$ In other words, the tails of the distribution could be thickening with an offsetting trend towards the middle. This would lead to little change in the standard deviation but could be construed as an example of increasing divergence.

In Figure 5, we assess this alternative story of polarization. We plot the proportion of the electorate in a each year with an ideal point more extreme than the middle $95 \%$ of the electorate in the previous year. In other words, each point is the proportion of respondents in that year whose ideal point is either less than the 2.5 th percentile or greater than the 97.5 th percentile of ideal points from the previous year. In a year in which the ideology of the electorate does not change at all, 5\% are more extreme than the middle 95\% - we represent this "no change" baseline by the grey dashed line. In years in which the number of ideal points in the tails increases, more than $5 \%$ will be outside of the previous year's middle 95\%. In years in which the number of ideal points in the tails decreases - when the distribution moderates - less than $5 \%$ will be outside the previous year's middle $95 \%{ }^{20}$ For example, if the 2.5 th percentile of the 1960 distribution was -1.5 , and the 97.5th percentile 1.5, and if the 1962 citizenry did not have more ideologues in the tails of the 1962 distribution, about 5 percent of the 1962 ANES respondents should have ideal points less than -1.5

\footnotetext{
${ }^{19}$ We should note that the ANES questions we use were not designed with the intention of discriminating between very extreme and mildly extreme ideologies, so our power to detect extreme voters - along with anyone else using the ANES - is limited to the response options given to the ANES respondents.

${ }^{20}$ One advantage of this statistic is that it assesses change in rank order, relaxing the assumption of cardinality of the ideal points required by summaries such as standard deviation.
} 
or greater than 1.5. If, however, the country became more polarized with more ideologues in these tails, we should observe more than 5 percent of the respondents with ideal points less than -1.5 or greater than 1.5. And, of course, the converse if the country became less polarized. This is why the dashed line at $5 \%$ is the benchmark of no change in polarization.

For voters plotted in the left frame, six of 26 years show a statistically significant increase in the proportion of ideal points in the tails. ${ }^{21}$ In the year with the largest shift out of the middle, 1970, less than $2 \%$ more of the electorate is in the previous year's tails. In many years, our point estimates are in the negative direction. The panel for senators in Figure 5 once again tells a notably different story. In 16 of 30 years, the proportion of senators outside of the previous congress's middle $95 \%$ rises significantly. ${ }^{22}$ All but five of the point estimates are above the 5\% line, and values range as high as $9 \%$. This is rather remarkable, because the bar for what constitutes "extreme" keeps rising by our criteria: every year is judged relative to the congress before. New members of the Senate consistently vote in the tails of the previous Senate's distribution of ideal points.

In summary, we find little evidence that the variation of ideology in the public has substantively increased from 1956 to 2012. In fact, the spread of ideology is consistent across this time period. We draw this conclusion both from the standard deviation of the distribution of ideal points, and from changes in the number of citizens in the tails of the prior year's distribution. We contrast this with a robust and steady trend of increasing divergence in the United States Senate.

\section{Party sorting}

Polarization may be a feature of the population as a whole, or it may be a feature of the ideology of different groups. It is possible that even in a population without increasing variance, people who identify with particular groups may sort themselves such that ideology becomes more divergent between groups. In the context of polarization, this has come to be known as "party sorting," where Democrats become more homogeneously liberal and Republicans more homogeneously

\footnotetext{
${ }^{21}$ We have run the results with a lower threshold for definition of the tails of the interior 75 percent of the distribution. Results are highly similar, and available from the authors on request.

${ }^{22}$ In the Senate, due to our identification of the scale by fixing senator locations, this divergence happens entirely due to replacement.
} 
conservative. In this section, we evaluate whether polarization has increased in the public by the definition of party sorting. We find consistent evidence for this hypothesis. The strongest version of sorting is an increase in party homogeneity, and the weakest is an increase in the divergence between the party medians. By any definition, senators are far more sorted than the public and have become increasingly so in this time period.

In Figure 6, we present the median ideal point of Democrats, Independents and Republicans, respectively, in each year for which we have data, for both the public and senators. ${ }^{23}$ For citizens, there are significant fluctuations over time. Although 2012 appears to be the most polarized year, most recent years were much less polarized, suggesting this may be a temporary state of affairs. The median Republican in 2008 is no more conservative than the median Republican in the 1960s. The move to the right in the late 1960s appears consistent with the conservative responses to that era such as the Goldwater presidential campaign and the beginnings of the anti-tax movement. Conservative Democrats were entering the Republican Party at that time due to the Democratic Party's stance on civil rights. In the mid 1990s, the Republicans move right and then back, consistent with initial enthusiasm for the Republican Revolution followed by disillusionment with government shutdowns. Although these changes are significant, it is difficult to know whether they are meaningful changes that drive behavior or temporary mood swings.

The location of the median Democrat has been more consistent over time than the location of the median Republican. Although Democrats were farther to the left in 2004 and 2008, they show little movement from 1956 to 2002. Overall, there has been a tendency for the distance between the two parties to increase.

Relative to the Senate, however, this sorting in the electorate is not particularly impressive. Although it seems as if the party medians in the public have grown farther apart, this is dwarfed by the almost doubling of the gap between the party medians in the Senate from the nadir in 1970 to 2012 (from a distance of 1.2 in 1970 to 2.3 in 2012). Republicans and Democrats alike moved to the left in the Civil Rights era, but the trend since 1970 has been one of monotonic divergence.

\footnotetext{
${ }^{23}$ We suppress the handful of independent senators from the by-party figures.
} 
In the public, homogeneity of ideal points within party shows a much more steady trend. In Figure 7, we present the posterior distribution of standard deviations of ideology in each party in each year. In the public, both parties have experienced declines of about $20 \%$ in the diversity of their membership, with the most notable decline occurring in the 1980s. Independents have also become less diverse, perhaps because independents with more ideological policy views have found a suitable party and remaining independents have tended to be in the middle of the ideological distribution. There are some significant fluctuations, but the trend from this graph appears more clear than the difference in party medians.

Once again, senator ideologies are much more homogenous within parties than voter ideologies, and have been for the entire series. In addition, within-party senate ideology has become more homogeneous over time at a steeper rate than among the public. Heterogeneity increased in the Republican party in the 1960s and 1970s, but since 1980 senators in both parties have become more homogenous, with a decline of close to $50 \%$ in standard deviation.

One dramatic change in Congress over the past 30 years has been the almost complete disappearance of overlap between the members of the two party caucuses. In the Senate, this disappearance is absolute and has been for some time. In Figure 8, we present a rank statistic on party overlap. We define the Democratic-Republican overlap region as the region of the ideological spectrum between the 95th percentile of ideology among Democrats and the fifth percentile of ideology among Republicans. For example, if in 1996 the 95th percentile of the distribution of Democrats is an ideology score of 0.25 and if the 5 th percentile of the distribution of Republicans is an ideology score of -0.25 , then the party overlap region in 1996 is from -0.25 to 0.25 . We calculate in each year (and on each MCMC iteration) the proportion of each party within that overlap region. Increases in polarization should correspond to decreases in the proportion in this overlap region.

In the current Senate, the proportion of members within the overlap region is $0 \%$ and has been so since 1986. This is because since that time, the 95th percentile Democrat has been to the left of the 5th percentile Republican, so there is no overlap in the distributions of ideology for the two 
parties. We plot the posterior distribution of the proportion of the public in the overlap region in the left panel of Figure 8. In the public, the proportion in the overlap region has usually been close to $80 \%$, but it has declined notably, to about $50 \%$ by 2012 . Figure 8 shows the decline started in the 1980s and accelerated through the 2000s. Because this same model estimates no increase in the variance of the public as a whole (Figure 4), the decrease in party overlap is attributable to the sorting of ideology to party and not to increases in the bimodality or variance of ideology in the public.

A final way we summarize the role that party groupings play in the overall variance is by decomposing total variance into the proportions attributable to between- and within-party variance. Consider two end-point examples for illustration of the statistic. In the first case, all Democrats have an ideal point of -1 , all independents an ideal point of 0 , and all Republicans an ideal point of 1 . Here, all population variance is attributable to between-party variance. In the second case, the ideal points of each party are distributed with mean 0 and variance 1 . In this case, all of the population variance is attributable to within-party variance, with no differences between parties. With party sorting present even in 1956, reality always falls somewhere in between these two cases. Polarization by this definition occurs when there is an increase in the variance attributable to between-party variance.

In Figure 9, we plot the posterior median proportion of all variance attributable to betweenparty variance along with $95 \%$ credible interval over time. In 1956, between-party variance made up less than 10 percent of all variance in ideology in the public. In 2012, it was near 40\%. With occasional dips, perhaps reacting to the failure of the Republican Revolution and the September 11 th attacks, the rise has been steady since the early 1980s. Nonetheless, the majority of variance in ideology remains attributable to variation within the parties. Although party sorting has been notable and measurable, it is far from complete.

In the Senate, sorting is approaching the level that we might expect from a parliamentary system, with between-party variance accounting for more than $90 \%$ of all variance. This trend has shown a relatively steady increase since the 1970s. However, the Senate has always been quite 
different from the public. The lowest year of between-party variance in the Senate is higher than the highest year in the public. With the exception of the 1960s, between-party variance has always accounted for a majority of the variance in positions in the Senate. This has never been true in the public.

The evidence presented here demonstrates a substantial change in the composition of the two parties in the Senate and in the public. With our results above showing no increase in standard deviation in the population as a whole, this compositional change in the parties can only be accounted for by a change in respondent choice of party identification correlated with respondent policy preferences. In the public, the overlap between the party distributions of ideology has always been, and remains, substantial. Variance within each political party has always accounted for a large majority of the variance in public views. In Congress, the middle is empty and differences between the parties account for more than $90 \%$ of the variance in policy positions.

\section{Alternative specifications}

In this section, we document robustness checks on our estimation of the distribution of ideology in the ANES. We consider three choices in our main estimation to make sure our finding of little polarization in the public and a modest amount of party sorting is not due to model assumptions. The three choices are the multinomial IRT specification, the collapsing of social issues into the single economic policy ideology dimension, and the assumption of constant item parameters, that is that the ANES policy questions have the same relationship to ideology over many years of the survey. In the online Appendix, we present the results of three alternative specifications of our estimation, and review the results briefly here.

We first consider whether the additional statistical power gained by assuming that the survey responses are ordered allows us to detect more polarization. In Appendix Section E.1, we present results of a model where responses are specified as ordered logit. Many of the issue questions on the ANES have what can be assumed to be a natural ordering ("strongly disagree," "disagree," "agree," "strongly agree," etc.), and assuming this ordering in the model specification may improve the statistical power to detect polarization. Our results, however, do not suggest any additional 
polarization when we make the ordered assumption. Frame (b) in Appendix Figures A4 to A10 reproduces each figure we present in the main body using the results of the ordered specification. To our view, no conclusions would be changed if we make the stronger assumption of an ordered logit specification.

We next consider social issues. Above, we estimated a single dimension of ideology for all policy questions, including economic and redistributive policy questions but also so-called "social issues." This specification assumes that social issues map onto the dominant economic dimension. Some have argued that social issues are a unique new front that may drive the polarization between liberals and conservatives, Democrats and Republicans. In order to test this possibility, in Appendix Section E. 2 we present the results of a model that looks only at social issues from 1980 to 2012, years in which enough questions are present to estimate the model. We include questions on school prayer, rights of the accused, the Equal Rights Amendment, women's equal role, abortion, discrimination against gays, gays in the military, and adoption of children by gay couples. Frame (c) in Appendix Figures A4 to A10 shows that we do not find large increases in polarization for social items only. There is an even smaller degree of party sorting on these social issues than on all issues, and as with our main evidence, the overall conclusion is of very limited change in the spread of ideology.

Finally, we consider the potential for changing meaning of policy preferences over time. Our main estimation assumes that policy questions asked in the 1950s have the same average relationship to ideology as they do in the 2010s. While this is an important component in allowing the distribution of ideology to be compared over time, it is a strong assumption. In order to relax this assumption while maintaining the comparability of the distribution over time, we allow policy questions to have different meanings during different periods, limiting the "run" of any policy question to 10 years or less. That is, we wrote an algorithm (we present $\mathrm{R}$ code for the algorithm and details of the estimation in Appendix Section E.3) that breaks policy questions fielded by the ANES more than 10 years apart into different items in our model so that no question is assumed to have the same relationship to ideology for more than 10 years. This leads to an estimation 
with 139 "different" policy questions. We produce a version of Figure 1 as Appendix Figure A11. Comparing the two provides intuition for the change in estimation assumptions.

Relaxing the assumption of constant meaning of policy preferences does not change our results. In Frame (d) of Appendix Figures A4 to A10, we show that the same figures we produce in the main body with the new estimation results look quite similar, and there is little evidence that conclusions would be altered. Allowing policy questions to have changed meaning over time does not evince greater evidence of either spread or sorting in the public in this time period.

In summary, we present in the On-line Appendix three alternative estimations to probe three assumptions of our main analysis. We find continued support for our main conclusions of small party sorting and no change in dispersion of the preferences of the American public from 1956 to 2012.

\section{Discussion}

The debate over polarization in the American public is far-ranging and important, but the evidence is limited. We argue that comparing the marginal proportions of the population giving specific survey responses is less effective to measure the construct of polarization than considering the structure of beliefs across political questions, just as has been done for Congress. In this article we estimated the same model of ideology for the American public and for Congress, used this model to compute metrics of polarization, and set the trends in polarization side by side for comparison.

Our results suggest that the public has not polarized in its policy views from 1956 to 2012. We show that the policy views of the public have a relatively stable distribution over time. What has changed is the sorting of the electorate into political parties. Members of the public better match their policy views to their political party than they did 60 or even 30 years ago. However, our evidence is wholly inconsistent with broader polarization. With respect to the policy questions in our data and the broader ideologies they represent, Americans tend to be no more distant from one another today than they were in the 1950s. The public has not "moved apart" on these questions of government policy. 
Our analysis is made possible by the use of a Bayesian Item Response Model. In addition to many of the usual statistics used to measure polarization or sorting, we also calculate statistics based on rank order so that we need not assume cardinality in the ideal points over time. Because we use Bayesian methods, we are able to straightforwardly characterize uncertainty about all statistics in both the Senate and the public, rank or otherwise. This allows us to make inferences about quantities that are commonly cited in the polarization debate but that have never been examined statistically, such as the degree of party overlap in Congress. For every statistic, we produce both an estimate for Congress and an estimate for the public. We argue that this methodological approach is an important step forward in the debate over polarization in the public.

The analysis here, especially highlighted by Figure 3, shows the importance of uncertainty in considering trends in polarization in the public. A first order problem is that changes in the number or types of items asked over time can lead to different levels of statistical power to detect spread in different years, and inaccurate attribution of changes in power to changes in polarization. A second order problem is that trends in polarization require defining some benchmark against which to compare year-over-year changes. One option is using the same policy or attitudinal question on the assumption that it has the same meaning over time, setting aside issues such as changes in status quo policy and measurement error. A second option, which we are argue is better but by no means infallible, is to consider multiple items in a common framework to allow measurement error and differential item functioning as much chance as possible to have limited effects on inference.

Importantly, our results suggest that the Senate has always had a far different structure of ideology than the public. The majority of variation in Senate ideology has always been between parties, and the majority of the variation in public ideology has always been within parties. This does not support the narrative that polarization, either divergence or sorting, has caused a "disconnect" or "breakdown" in American politics. Senators are much more homogenous in their views within parties. This means that most members of the public, throughout this time period, have been represented by representatives that are quite dissimilar from them, even if they share the same party. Moreover, trends in dispersion between these parties have not been matched by greater dis- 
persion in public ideology. If this is a breakdown of representation or government more broadly, then government has always been broken. Research on the electoral linkage is fundamental to understanding why legislators are loosely tethered to the ideology of their constituents, and what significance this has for the functioning of the broader political system.

\section{References}

Abramowitz, A.I. 2010. The Disappearing Center: Engaged Citizens, Polarization, and American Democracy. Yale University Press.

Abramowitz, Alan, and Kyle Saunders. 2005. "Why can't we all just get along? The reality of a polarized America." In The Forum. Vol. 3 pp. 1-22.

Abramowitz, Alan I, and Kyle L Saunders. 2008. "Is polarization a myth?" Journal of Politics 70(2): 542-55.

Aldrich, John H, and Richard D McKelvey. 1977. "A Method of Scaling with Applications to the 1968 and 1972 Presidential Elections." The American Political Science Review pp. 111-130.

Ansolabehere, Stephen, Jonathan Rodden, and James M Snyder. 2008. "The strength of issues: Using multiple measures to gauge preference stability, ideological constraint, and issue voting." American Political Science Review 102(02): 215-232.

Bafumi, Joseph, and Michael C Herron. 2010. "Leapfrog representation and extremism: A study of American voters and their members in Congress." American Political Science Review 104(03): 519-542.

Baldassarri, Delia, and Andrew Gelman. 2008. "Partisans without Constraint: Political Polarization and Trends in American Public Opinion.” American Journal of Sociology 114(2): 408-446.

Carroll, Royce, Jeffrey B. Lewis, James Lo, Keith T. Poole, and Howard Rosenthal. 2009. "Measuring Bias and Uncertainty in DW-NOMINATE Ideal Point Estimates via the Parametric Bootstrap." Political Analysis 17(3): 261-275.

Clinton, Joshua D, Simon Jackman, and Doug Rivers. 2004a. "The most liberal senator? analyzing and interpreting congressional roll calls." Political Science and Politics 37(04): 805-811.

Clinton, Joshua, Simon Jackman, and Douglas Rivers. 2004b. "The statistical analysis of roll call data." American Political Science Review 98(02): 355-370.

Fiorina, Morris P, and Samuel J Abrams. 2008. "Political polarization in the American public." Annual Review of Political Science 11: 563-588.

Fiorina, Morris P, Samuel A Abrams, and Jeremy C Pope. 2008. "Polarization in the American public: Misconceptions and misreadings." The Journal of Politics 70(02): 556-560. 
Fiorina, Morris P, Samuel J Abrams, and Jeremy Pope. 2005. Culture war? Pearson Longman New York.

Fiorina, M.P., and S.J. Abrams. 2012. Disconnect: The Breakdown of Representation in American Politics. Julian J. Rothbaum Distinguished Lecture Series University of Oklahoma Press.

Jackman, Simon. 2009. Bayesian analysis for the social sciences. Vol. 846 John Wiley \& Sons.

Jacobson, Gary C. 2003. Partisan polarization in presidential support: The electoral connection. In Congress \& the Presidency: A Journal of Capital Studies. Vol. 30 Taylor \& Francis pp. 1-36.

Jacobson, Gary C. 2004. "Explaining the Ideological Polarization of the Congressional Parties since the 1970s." Available at SSRN 1157024.

Jacoby, William G. 1994. "Public attitudes toward government spending." American Journal of Political Science pp. 336-361.

Jessee, Stephen A. 2009. "Spatial voting in the 2004 presidential election." American Political Science Review 103(1): 59-81.

Krasa, Stefan, and Mattias Polborn. 2014. "Social Ideology and Taxes in a Differentiated Candidates Framework." American Economic Review 104(1): 308-322.

Layman, Geoffrey C., and Thomas M. Carsey. 2002. "Party Polarization and 'Conflict Extension' in the American Electorate.” American Journal of Political Science 46(4): pp. 786-802.

Layman, Geoffrey C, Thomas M Carsey, John C Green, Richard Herrera, and Rosalyn Cooperman. 2010. "Party polarization, party commitment and conflict extension among American party activists.” American Political Science Review 104(2): 324-346.

Levendusky, Matthew. 2009a. The partisan sort: How liberals became Democrats and conservatives became Republicans. University of Chicago Press.

Levendusky, Matthew S. 2009b. "The Microfoundations of Mass Polarization.” Political Analysis 17(2): 162-176.

Levendusky, Matthew S. 2010. "Clearer cues, more consistent voters: A benefit of elite polarization." Political Behavior 32(1): 111-131.

Lo, James. 2010. “Essays on Preferences in Political Science.” Ph.D. Dissertation. Los Angeles, CA: University of California, Los Angeles.

McCarty, Nolan M, Keith T Poole, and Howard Rosenthal. 2006. Polarized America: The dance of ideology and unequal riches. mit Press Cambridge, MA.

Plummer, Martyn. 2013a. JAGS: A Program for Analysis of Bayesian Graphical Models Using Gibbs Sampling. International Agency for Research on Cancer.

Plummer, Martyn. 2013b. rjags: Bayesian graphical models using MCMC. 
Poole, Keith T, and Howard Rosenthal. 1984. "The polarization of American politics.” The Journal of Politics 46(04): 1061-1079.

Poole, Keith T, and Howard Rosenthal. 2000. Congress: A political-economic history of roll call voting. Oxford University Press on Demand.

Tausanovitch, Chris, and Christopher Warshaw. 2013. "Measuring Constituent Policy Preferences in Congress, State Legislatures, and Cities." Journal of Politics 75(3).

Theriault, Sean M. 2006. "Party Polarization in the US Congress Member Replacement and Member Adaptation." Party Politics 12(4): 483-503.

Treier, Shawn, and D Sunshine Hillygus. 2009. "The nature of political ideology in the contemporary electorate." Public Opinion Quarterly 73(4): 679-703. 


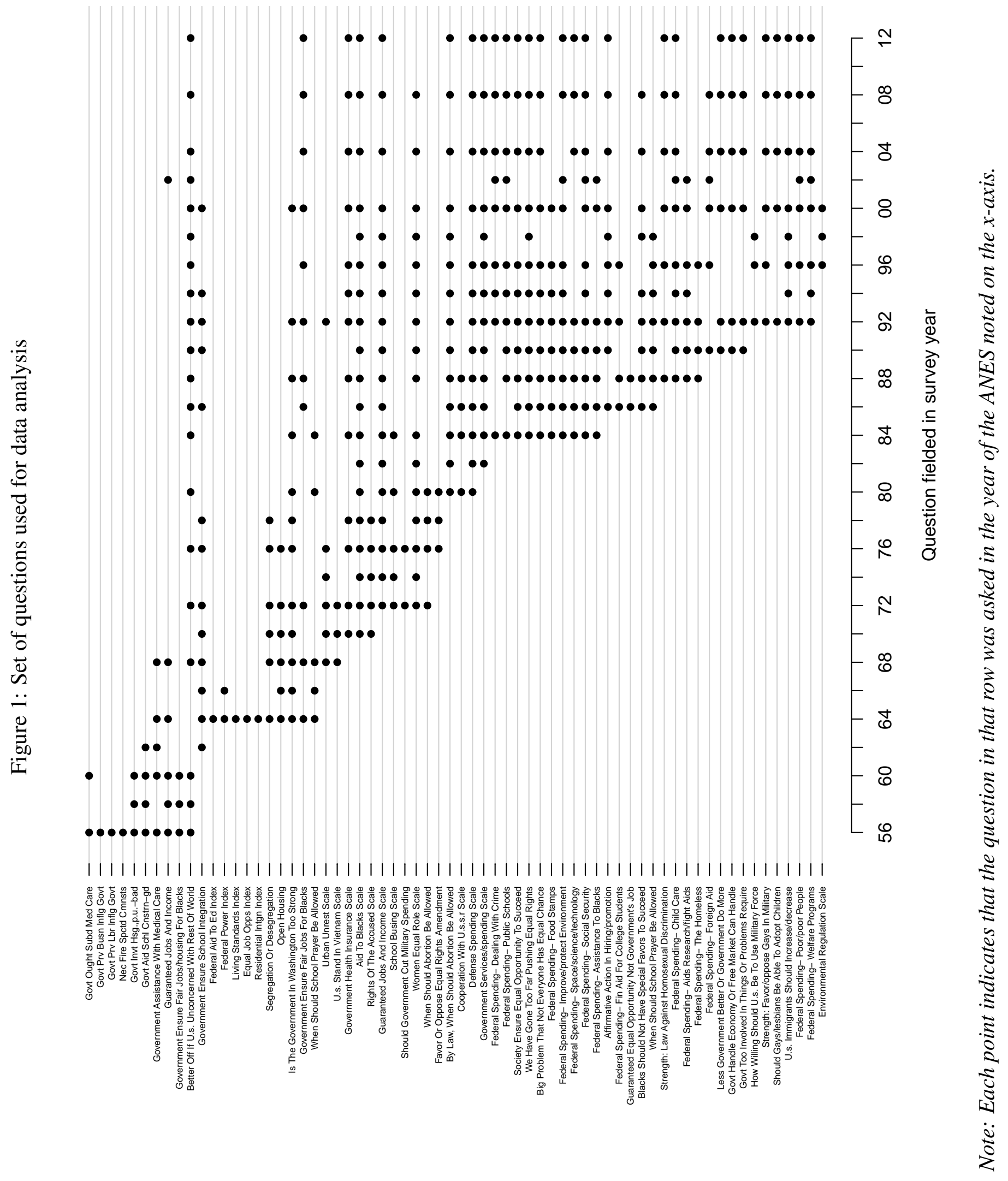



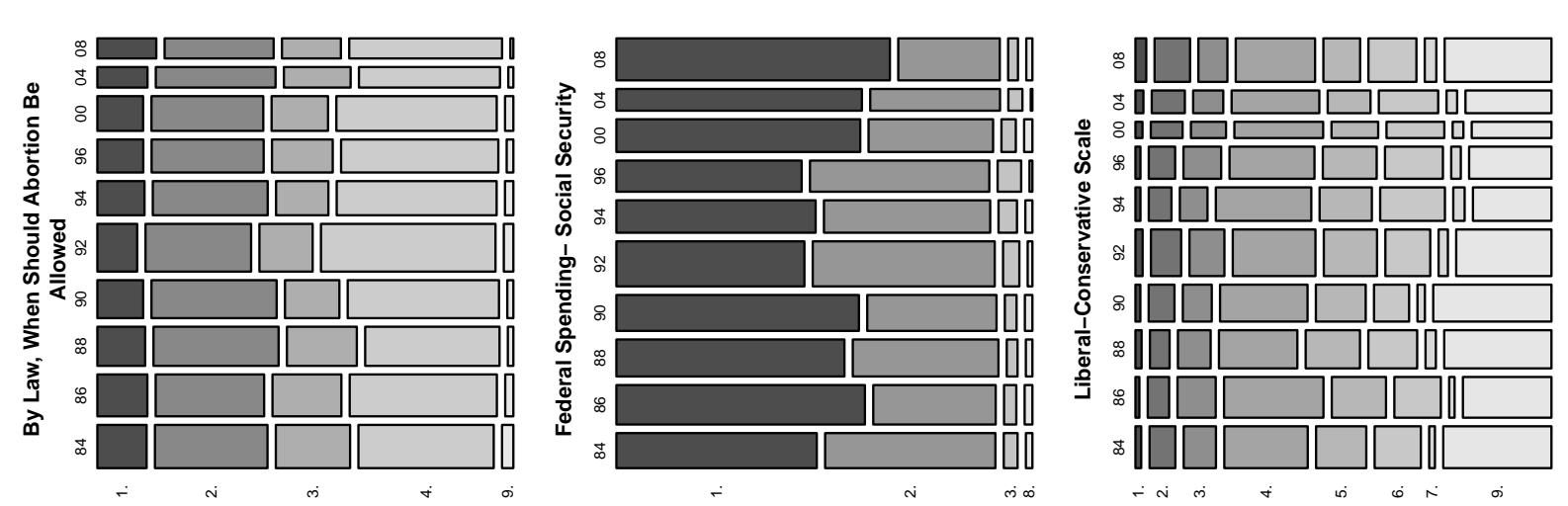

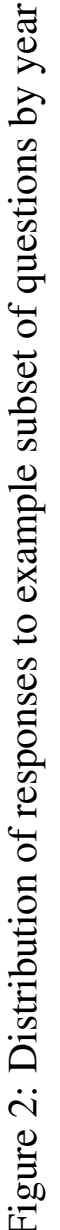
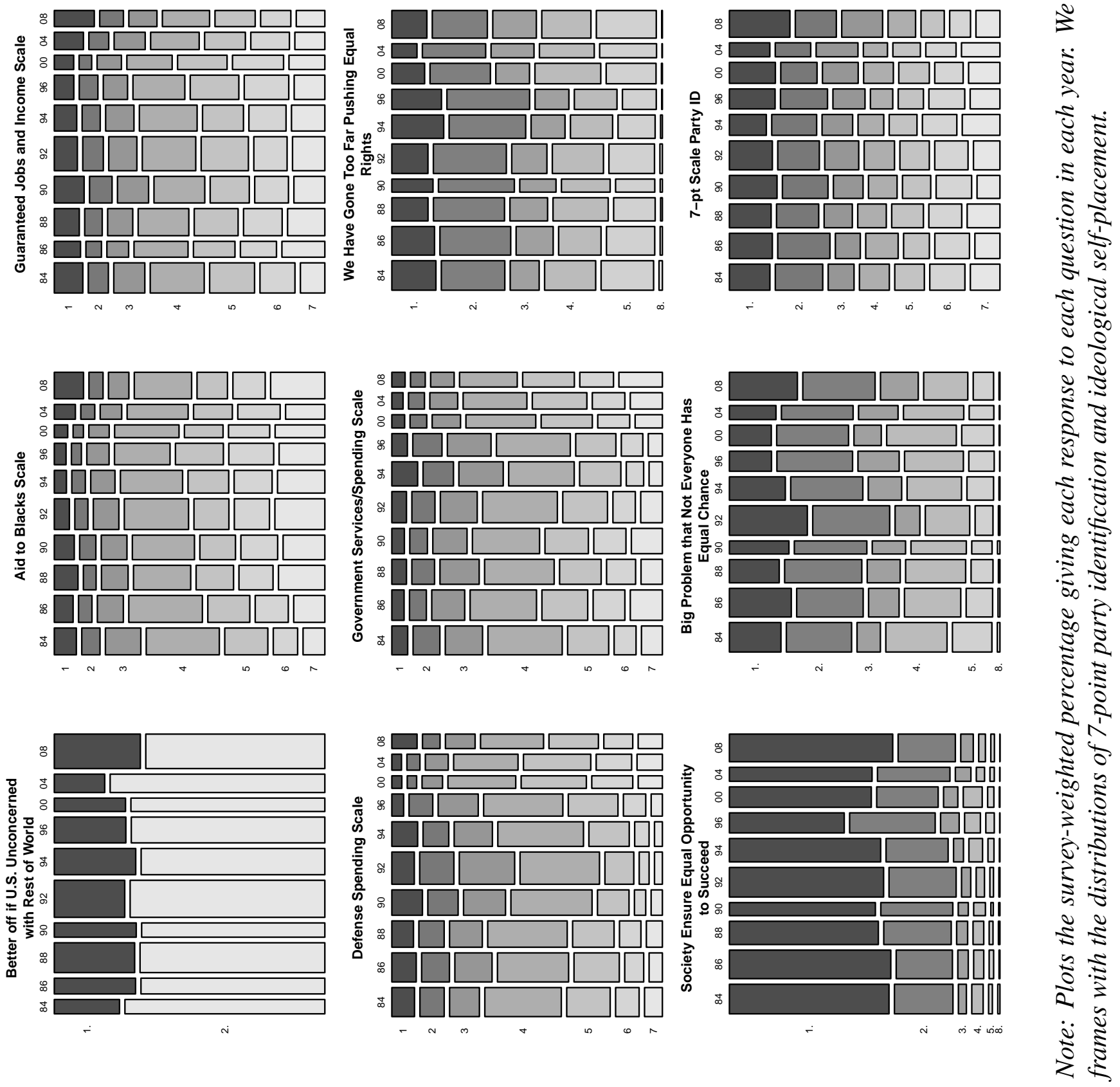


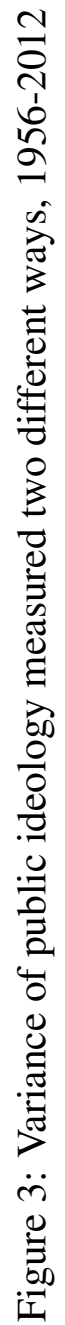

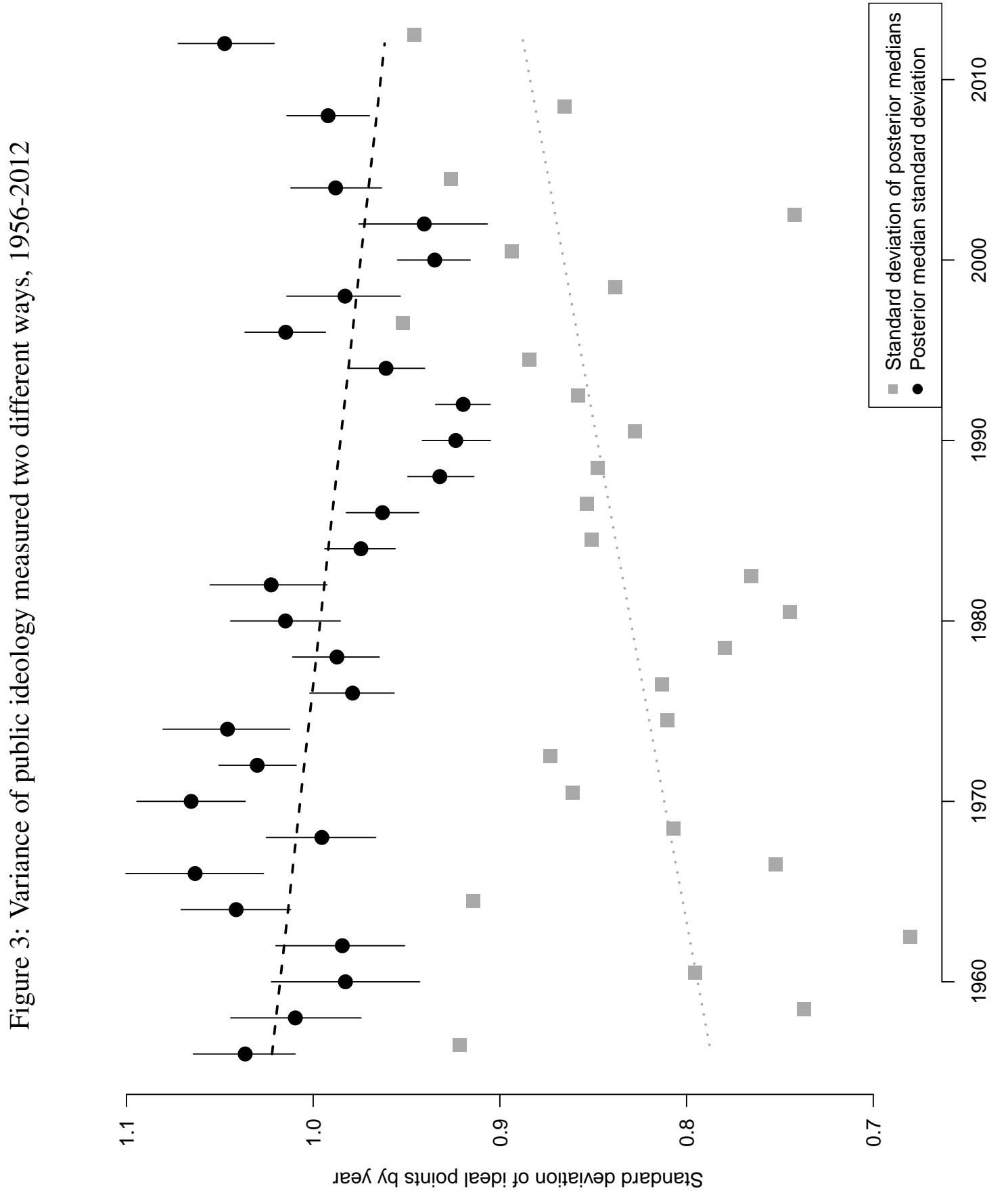

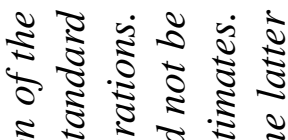

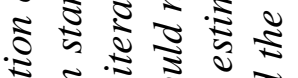

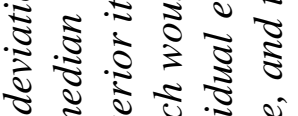

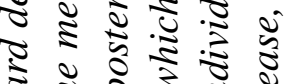

$\frac{1}{8} 5 \sqrt{2} 5.5$

胥苂.

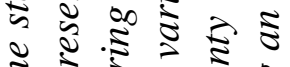

$\leq \frac{2}{2}$

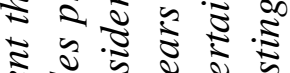

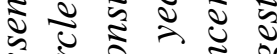

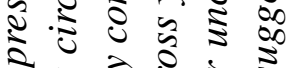

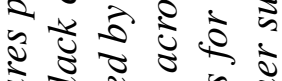

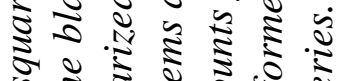

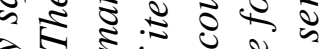

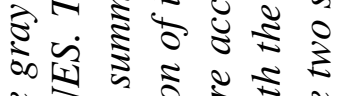

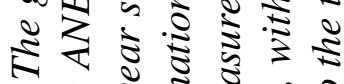

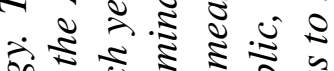

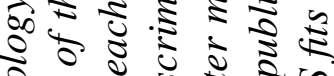

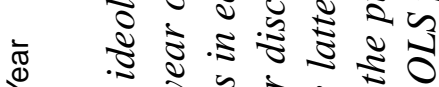

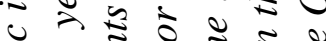

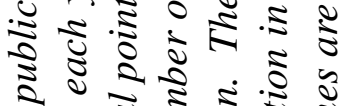

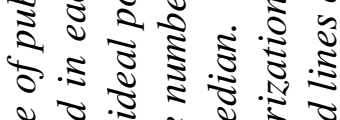

竎永 0

.

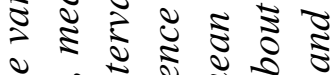

₹.

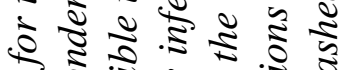

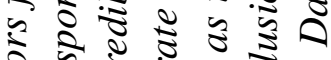

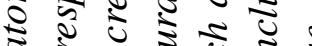

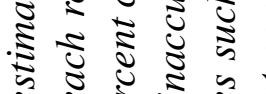

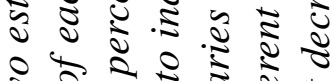

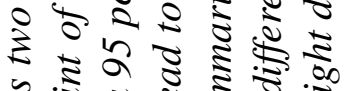

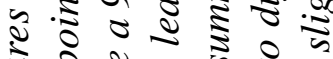

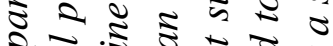

ㄱำ

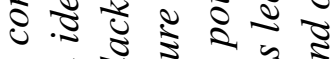

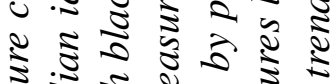

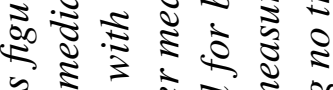

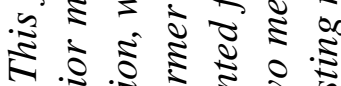

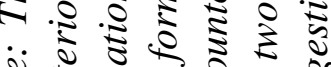
i 5.500 之ं है है 


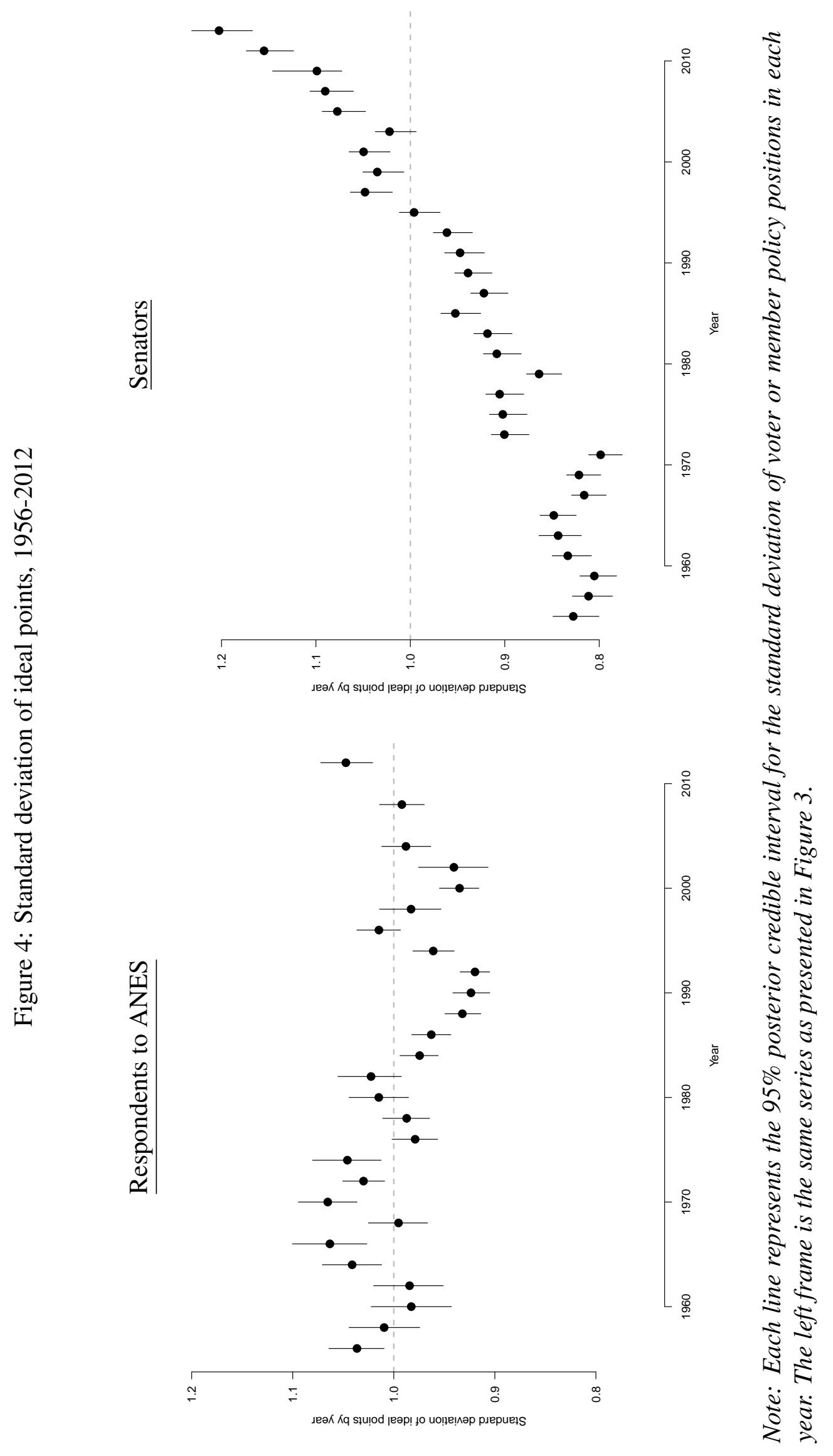




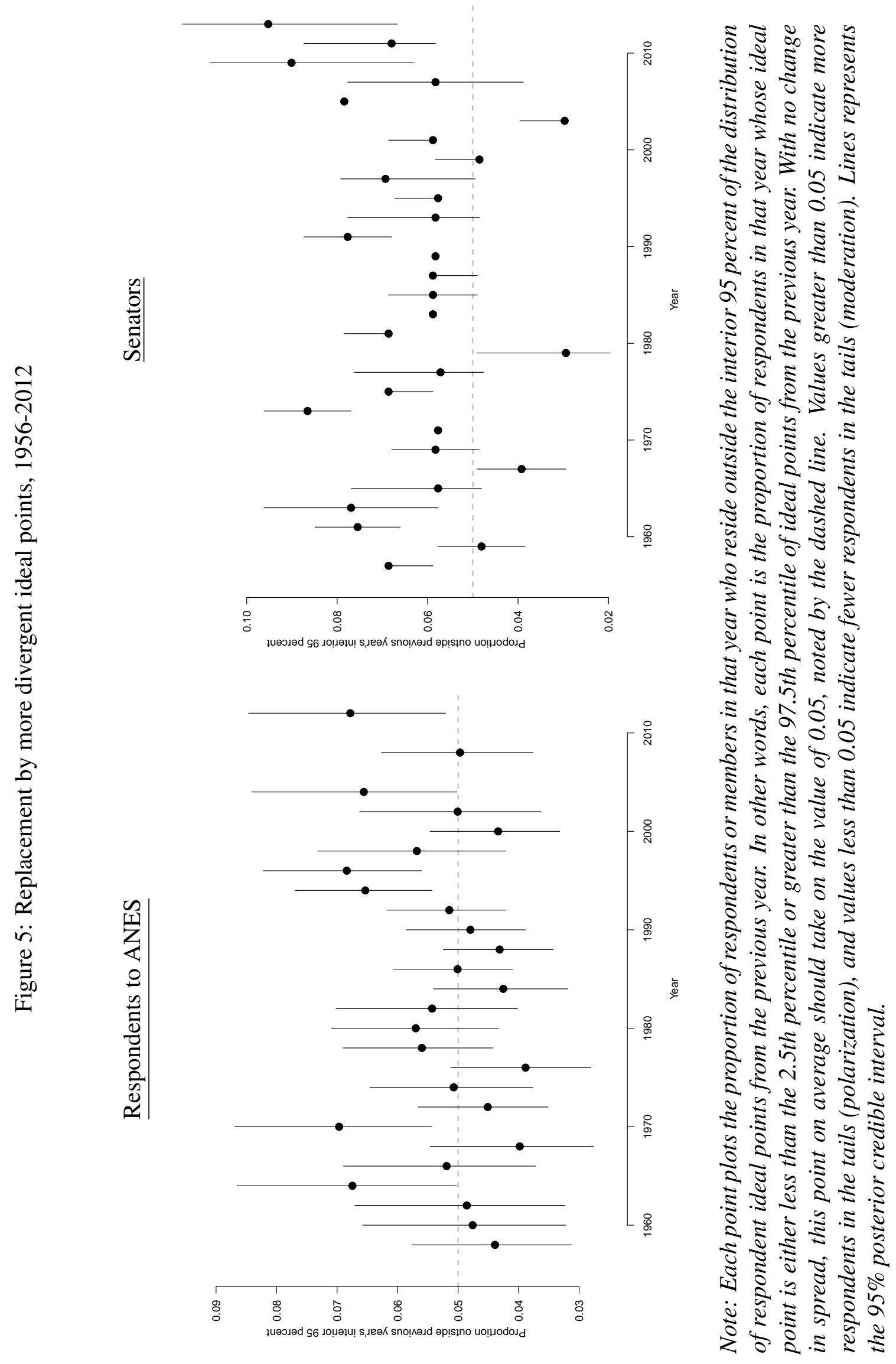




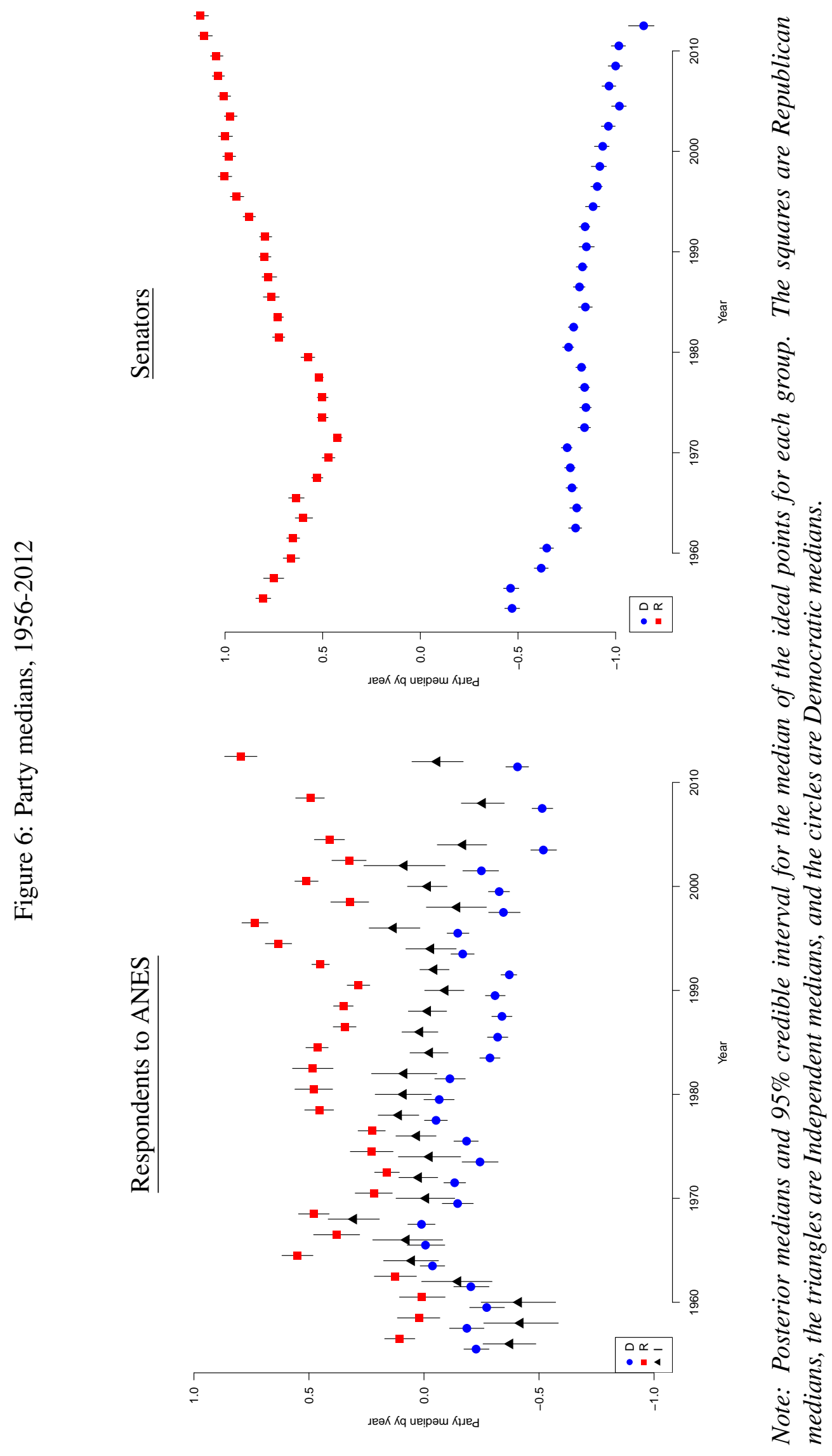




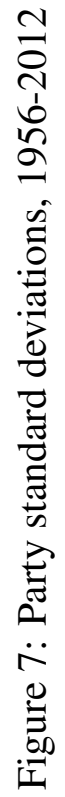

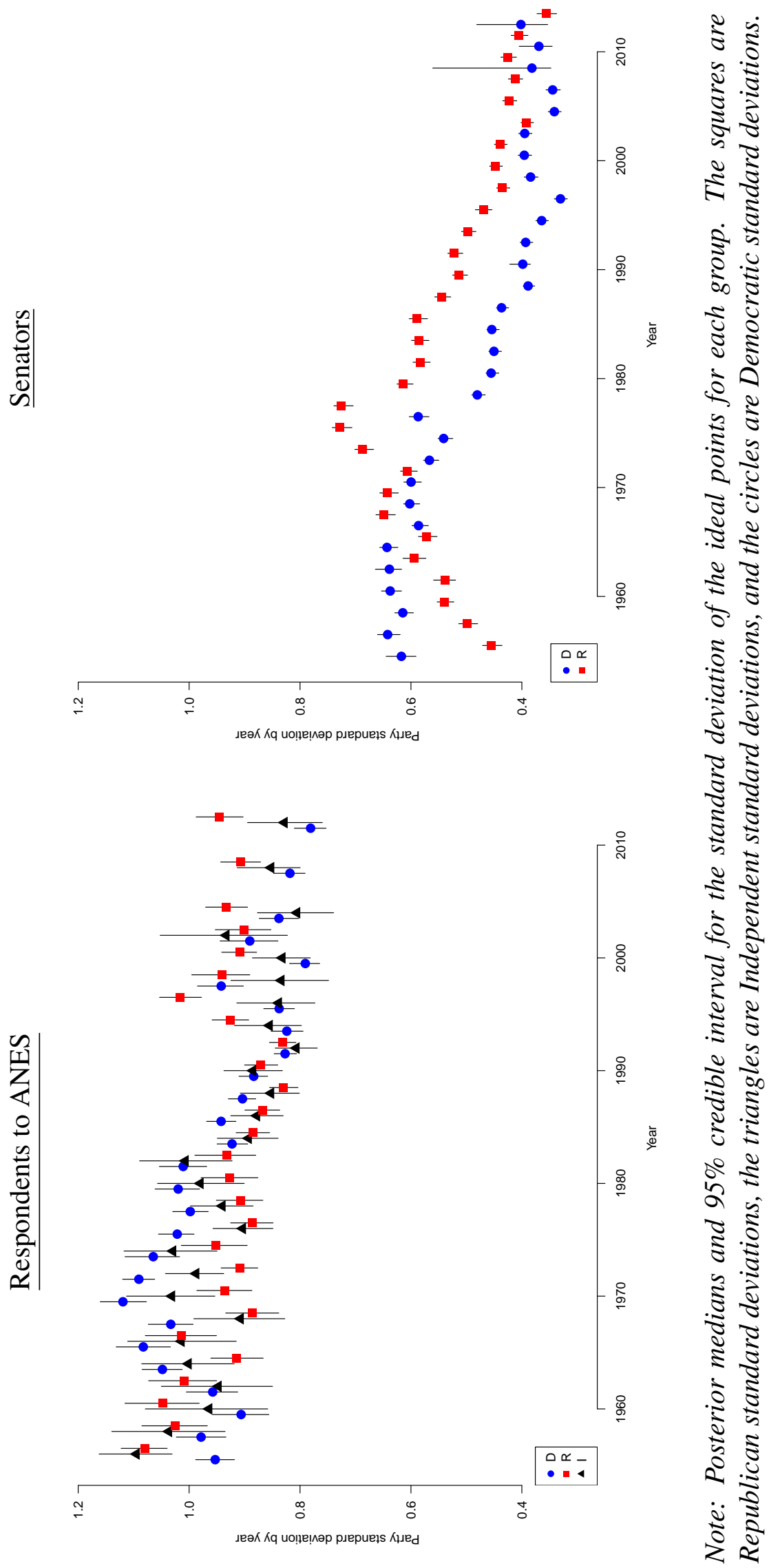




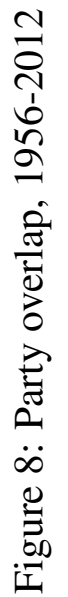

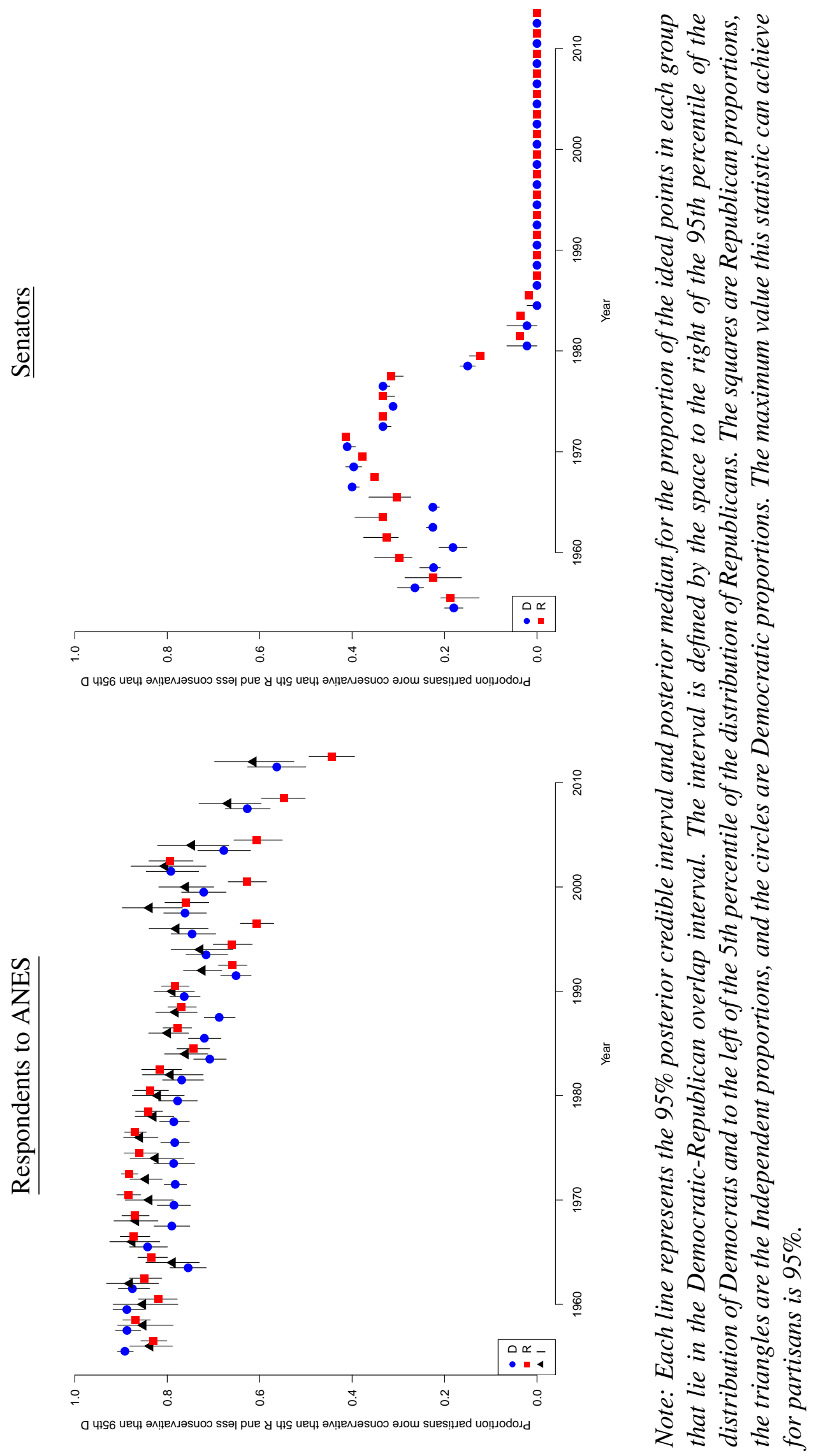




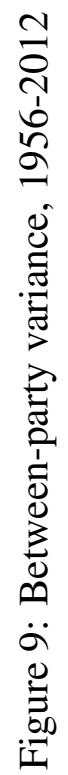
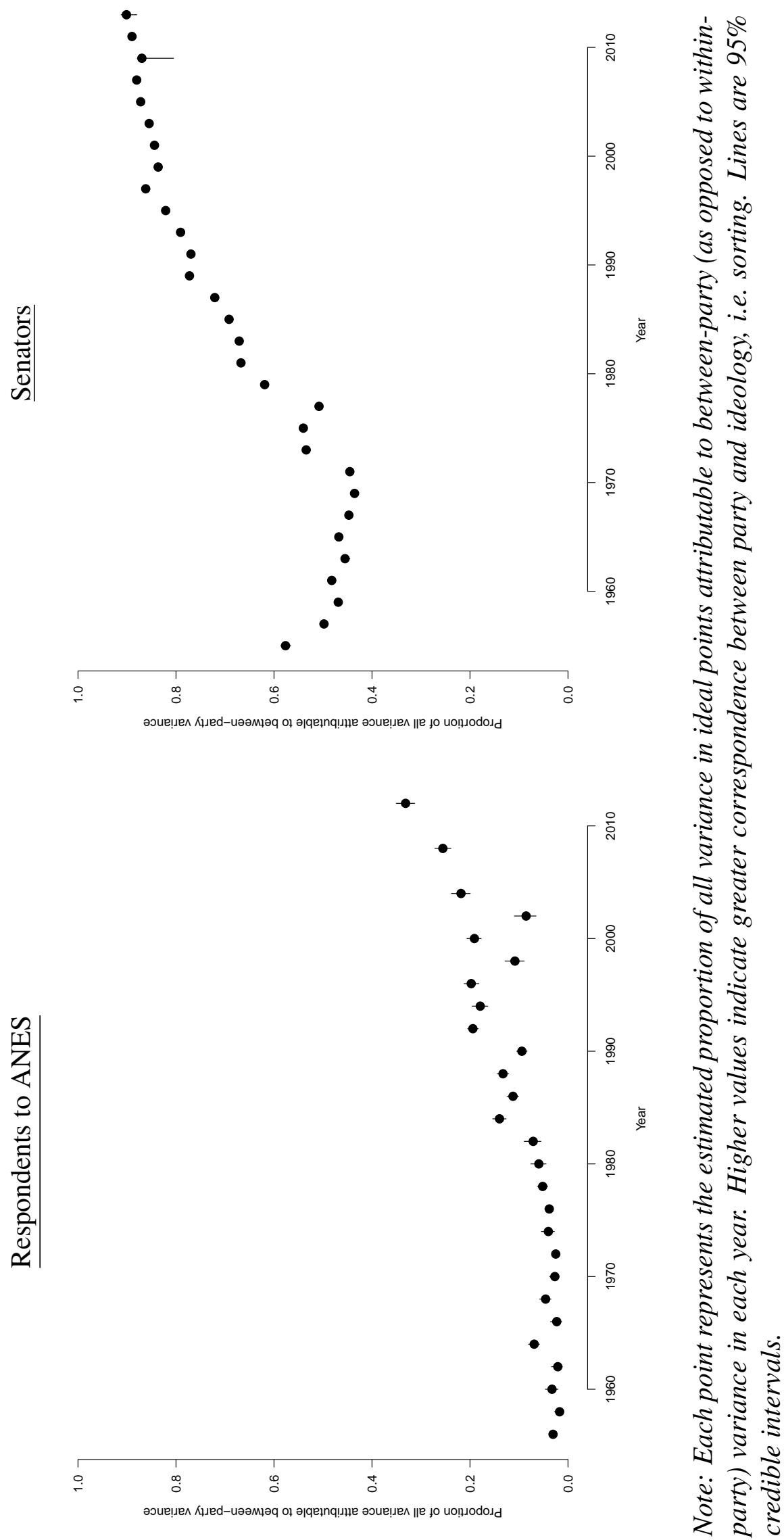